\title{
Clinical Characteristics and Prognostic Factors of Primary Splenic Angiosarcoma: A Retrospective Clinical Analysis from China
}

\author{
Rong Lia,b Ming Lia,b Lin-fang Zhang ${ }^{a, b} \quad$ Xiao-ming Liu ${ }^{a, b} \quad$ Ting-zi Hu $u^{a, b}$ \\ Xiu-Juan Xia ${ }^{a, b}$ Jing-shu Chi ${ }^{a, b}$ Xiao-xia Jiang ${ }^{a, b}$ Can-xia Xu, \\ aDepartment of Gastroenterology, Third Xiangya Hospital of Central South University, Changsha, \\ Hunan, ${ }^{b}$ Hunan Key Laboratory of Nonresolving Inflammation and Cancer, Changsha Hunan, P.R. China
}

\section{Key Words}

Primary splenic angiosarcoma $\bullet$ Clinical characters $\bullet$ Treatment $\bullet$ Chemotherapy $\bullet$ Prognosis

\begin{abstract}
Background/Aims: Primary splenic angiosarcoma is an aggressive malignancy originating from endothelial cells with a particularly poor outcome despite radical therapy. Owing to its extremely low incidence, available data for splenic angiosarcoma are limited. The present study aimed to address this limitation by presenting a thorough retrospective analysis of Chinese primary splenic angiosarcoma patients over a 53-year period (1963-2016). Methods: To determine the characteristics of Chinese primary splenic angiosarcoma and identify factors that impact the outcomes of this histology, we retrospectively retrieved reports of 110 Chinese primary splenic angiosarcoma cases published between 1963-2012. Results: In total, 61 males and 49 females diagnosed with primary splenic angiosarcoma were included in the present study. The median age at diagnosis was 50 years (range $2.5-76$ years). Of these patients, $25.5 \%$ had received prior radiotherapy. The rate of splenic rupture was $59.11 \%$. The 1 -year overall survival rate was $19.1 \%$ with a median overall survival time of 8.1 months. Age, gender, and radiation history showed no correlation with survival rate. However, by univariate analysis, we found that significant adverse predictors of survival were splenic rupture before surgery and large tumor size ( $>5 \mathrm{~cm}$ ), while adjuvant chemotherapy was a favorable predictor. Furthermore, multivariate analysis revealed that splenic rupture and adjuvant chemotherapy were independent adverse and favorable predictors, respectively. Conclusion: Our large series describes and confirms the characteristics and poor prognosis of Chinese primary splenic angiosarcoma, thus indicating a critical role for early diagnosis and surgical intervention (prior to rupture) in management, and highlights the promising potential of adjuvant chemotherapy for improving the outcome in these cases.

(C) 2018 The Author(s)




\section{Cellular Physiology Cell Physiol Biochem 2018;49:1959-1969 \\ \begin{tabular}{ll|l} 
and Biochemistry & $\begin{array}{l}\text { DOI: 10.1159/000493656 } \\
\text { Published online: } 21 \text { September, } 2018\end{array}$ & $\begin{array}{l}\text { C } 2018 \text { The Author(s). Published by S. Karger AG, Basel } \\
\text { www.karger.com/cpb }\end{array}$ \\
\hline
\end{tabular}}

\section{Introduction}

The spleen is regarded as an important immune organ, and it is rarely reported as a primary tumor site. Angiosarcoma is an unusual and highly malignant neoplasm arising from vascular endothelial cells with a high metastatic rate [1-4]. Primary splenic angiosarcoma (PSA) is the most unusual type of splenic malignancy with early multifocal metastasis through hematogenous spread. It has been reported that PSA originates from immature endothelial-type cells [5]. The incidence of PSA has been reported between 0.15 and 0.26 per million people $[6,7]$.

Owing to the very low incidence and a lack of systematic analysis, the epidemiology, etiology, clinical diagnosis and treatment of PSA remain challenging. The initiation of PSA has been reported to have an association with environmental or occupational exposure to carcinogens (vinyl chloride, thorium dioxide, arsenic or radiation) and benign splenic hemangioma $[8,9]$. However, no clear relationship between these factors has been robustly established. In most cases, no obvious causative factors can be identified. PSA tends to occur more often in the older age population, while younger cases have also been reported [10, 11]. A slight male predilection among the reported PSA cases has been reported [12]. The common presentations are non-specific and include weakness, fatigue, abdominal distension, abdominal pain, anorexia, and weight loss. Occasionally, PSA presents as an abdominal emergency or uncontrolled hemorrhagic shock due to the high rate of spontaneous splenic rupture in PSA [6]. A minority of patients are asymptomatic with PSA discovered incidentally. Physical examination does not always provide a direct diagnosis. In addition to splenomegaly, the patients may have abdominal tenderness, jaundice or hepatomegaly, or even ascites when there is metastasis [7]. On laboratory examination, anemia and thrombocytopenia are the most common blood abnormalities [13], though schistocytes and echinocytes have also been reported [14].

The highly malignant character and non-specific symptoms very often result in delayed diagnoses for PSA patients. Moreover, the therapeutic strategies for PSA are limited due to its extreme rarity and highly aggressive characteristics. Consequently, the prognosis of PSA is poor. Although the longest documented surviving case was a boy who remained diseasefree at 14.8 years after surgery [10], an average survival time of less than 6 months has been implicated for PSA, irrespective of the type of treatment administered [7].

Since the first case reported by Theodor Langhans in 1879, only approximately 300 cases have been reported in the literature worldwide, largely as isolated case reports [11, 15]. Large-scale systemic analyses are still lacking. Moreover, research on PSA prognosis is also limited. As a result, this disease remains very challenging for even experienced clinicians. Therefore, the present study has retrospectively collected information from 110 Chinese PSA cases reported from 1963 to 2017, including general data, clinical characteristics and prognostic information, in order to identify potential factors involved in the occurrence of PSA and explore potential prognostic indicators.

\section{Materials and Methods}

Case retrieval

We systematically searched the online Chinese databases (Wanfang, VIP and CNKI; updated through March 1, 2017) with the search term "primary splenic angiosarcoma" in Chinese. Concurrently, the PubMed and Web of science databases were also searched with "primary splenic angiosarcoma (haemangiosarcoma)" or "primary spleen angiosarcoma (haemangiosarcoma)" and "China (Chinese)" as search terms. Two investigators (Rong $\mathrm{Li}$ and Ming $\mathrm{Li}$ ) independently screened all titles and abstracts to identify eligible studies. We collected the demographic and clinicopathological information on all reported cases, including year, gender, age, abdominal radiotherapy history, tumor characteristics, clinical manifestation, treatment modality (surgery or adjuvant therapy) and prognosis. Follow-up information was also collected, and overall 


\section{Cellular Physiology $\quad$ Cell Physiol Biochem 2018;49:1959-1969

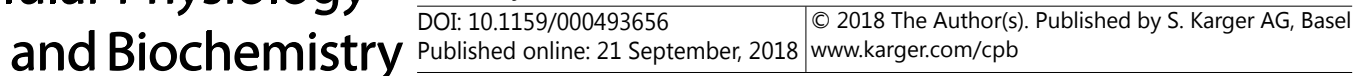

survival (OS) was defined as the period of time from the initial diagnosis of primary splenic angiosarcoma to death from any cause or last follow-up.

\section{Case selection}

In this study, cases were selected from published reports according to the following criteria: (1) case report of primary splenic angiosarcoma with a clear diagnosis, clinical-pathological characteristics documented and prognostic information reported; and (2) overviews of primary splenic angiosarcomas with summarized clinical information. Unpublished cases, meeting abstracts, comments, letters and literature reviews were not included. All of the 110 cases were diagnosed with histologic confirmation. However, only 66 of 110 cases had detailed histological information reported.

\section{Statistical analysis}

SPSS software (version 16.0, Chicago, IL) was used for statistical analyses in this study. All data are presented as the mean \pm standard deviations (SD). Categorical variables were compared by $\chi 2$ or Fisher's exact test. Survival curves were drawn using the Kaplan-Meier method, and differences in survival times were tested with the log-rank test. Univariate and multivariate analyses were performed using the Cox proportional hazard model. All tests were two-tailed, and $p<0.05$ was considered to be statistically significant.

\section{Results}

\section{Clinical characters of PSA}

Data from 110 Chinese splenic angiosarcomas were extracted from published reports of 96 PSA cases identified through a comprehensive search of PubMed, Web of science and Chinese databases (Wanfang, VIP and CNKI) through March 1, 2017. As displayed in Table 1, 69 males and 41 females were diagnosed with splenic angiosarcoma in China, which indicates a propensity among Chinese males. The age of onset in patients with splenic angiosarcoma varied greatly from 2.5 to 76 years old. Thirty-three cases were diagnosed before 2000 , and 77 cases were diagnosed between 2000-2017, suggesting an increasing incidence.

As this tumor originates from the vascular cells with a highly malignant character, over half of the patients were diagnosed with a large mass $(>5 \mathrm{~cm})$ and 76 patients had metastatic disease at diagnosis. Spontaneous splenic rupture was frequently observed $(n=65)$. Among the 110 cases, a total of 46 patients underwent emergency surgery due to uncontrollable bleeding caused by splenic rupture or metastatic lesions.

Similar to angiosarcoma in other organs, the pathogenesis

Table 1. The clinicopathological characteristics of 110 patients. NA. Not available

\begin{tabular}{|c|c|c|}
\hline Characteristics & $\begin{array}{l}\text { Number of } \\
\text { patients }\end{array}$ & $\%$ \\
\hline \multicolumn{3}{|l|}{ Gender } \\
\hline Male & 69 & 62.7 \\
\hline Female & 41 & 37.3 \\
\hline \multicolumn{3}{|l|}{ Age } \\
\hline$\leq 60$ & 26 & 23.6 \\
\hline$>60$ & 84 & 76.4 \\
\hline \multicolumn{3}{|l|}{ Year } \\
\hline$\leq 2000$ s & 33 & 30 \\
\hline$>2000 s$ & 77 & 70 \\
\hline \multicolumn{3}{|l|}{ Size } \\
\hline$\leq 5 \mathrm{~cm}$ & 53 & 48.2 \\
\hline$>5 \mathrm{~cm}$ & 57 & 51.8 \\
\hline \multicolumn{3}{|l|}{ Metastasis at diagnosis } \\
\hline Yes & 76 & $69.1 \%$ \\
\hline No & 34 & $30.9 \%$ \\
\hline \multicolumn{3}{|l|}{ Splenic rupture prior to surgery } \\
\hline Yes & 65 & 59.1 \\
\hline No & 45 & 40.9 \\
\hline \multicolumn{3}{|l|}{ Abdominal radiotherapy } \\
\hline With & 28 & 25.5 \\
\hline Without & 82 & 74.5 \\
\hline \multicolumn{3}{|c|}{ History of benign spleen hemangioma } \\
\hline Yes & 29 & 26.4 \\
\hline No & 81 & 73.6 \\
\hline \multicolumn{3}{|l|}{ Approach to diagnose } \\
\hline Fine needle aspiration biopsy & 15 & 13.6 \\
\hline Surgic sample & 95 & 86.4 \\
\hline \multicolumn{3}{|l|}{ Adjuvant chemotherapy } \\
\hline Yes & 31 & 28.2 \\
\hline No & 79 & 71.8 \\
\hline \multicolumn{3}{|l|}{ Emergency surgery } \\
\hline Yes & 46 & 41.8 \\
\hline No & 64 & 58.2 \\
\hline
\end{tabular}




\section{Cellular Physiology Cell Physiol Biochem 2018;49:1959-1969 \\ \begin{tabular}{ll|l} 
and Biochemistry & $\begin{array}{l}\text { DOI: 10.1159/000493656 } \\
\text { Published online: } 21 \text { September, } 2018\end{array}$ & $\begin{array}{l}\text { C) } 2018 \text { The Author(s). Published by S. Karger AG, Base } \\
\text { www.karger.com/cpb }\end{array}$ \\
\hline
\end{tabular}}

of splenic angiosarcoma is obscure. Although exposures to particular toxins or radiation have been implicated as possible causes, clear exposure history was not available for most patients in our study. There were 28 patients with an explicit exposure to radiation for radiotherapy or occupational demands. Only 3 patients displayed a definitive family history of cancer. More interestingly, a total of 29 patients had been initially diagnosed with benign spleen hemangiomas, some for an extended period of time. However, they continued to seek further treatment, due to rapid increases in tumor mass, until they eventually received a clear diagnosis of splenic angiosarcoma. All 110 splenic angiosarcoma cases were diagnosed with histologic confirmation. However, detailed histological information was only available for 66 cases. Vasoformative architecture was described in 30 $(45.5 \%)$ cases. Of the $36(54.5 \%)$ nonvasoformative angiosarcomas, 18 had epithelioid morphology, 8 had spindle cell morphology, and 10 cases were mixed. Of the 28 radiation-associated splenic angiosarcomas, 10 cases displayed vasoformative architecture. As PSA tumors have a tendency to spread, it was not surprising that all patients in this study developed a secondary lesion; the most common secondary organ site was the liver, followed by the lungs and the peritoneal cavity (Table 2). Combined with non-specific clinical presentations, the extremely low incidence of angiosarcoma made quick and accurate diagnosis very difficult. As a result, misdiagnosis was very common. According to our results, clear diagnosis at first hospital duration was rare, even after a thorough clinical inquiry and physical examination. The most common misdiagnoses are listed in Table 2. Due to the non-specific clinical presentations and a lack of serum specific biomarkers, most splenic angiosarcomas were ultimately diagnosed by surgery and subsequent pathologic evaluation. In addition, there were 15 patients who were correctly diagnosed on the basis of a fine needle aspiration (FNA) biopsy of the spleen, demonstrating a diagnostic advantage of this minimally invasive method. In addition, there were 15 patients who were correctly diagnosed on the basis of a fine needle aspiration (FNA) biopsy of the spleen, demonstrating a diagnostic advantage of this minimally invasive method. All of the patients enrolled received therapeutic surgery, and 31 patients were treated with subsequent adjuvant chemotherapy.

\section{The characteristics of radiotherapy-induced splenic angiosarcoma}

According to the potential cause of disease, angiosarcomas are divided into cutaneous angiosarcoma, primary-breast angiosarcoma, soft-tissue angiosarcoma, lymphoedemaassociated angiosarcoma and radiation-induced angiosarcoma [16]. Radiation therapy has been widely used and established to be an efficacious treatment for some tumor types including breast cancer, cervical cancer and uterine cancer. Notably, most documented cases of post-radiation angiosarcomas have been reported in breast, skin and associated soft tissue [17]. In the present study, we have retrospectively detected 28 cases of radiation-induced 
splenic angiosarcoma (RSA) among the 110 PSA cases. Radiation therapy was initially employed in the adjuvant setting for all cases. Consistent with the features of reported radiationrelated angiosarcomas [18, 19], the average interval between radiation exposure and presentation of RSA was approximately 9.5 years and ranged from 4 to 21 years. Herein, we have analyzed the association between clinical characteristics and the occurrence of RSA. As displayed in Table 3, there were more cases of RSA among the females $(15 / 41$ vs. $13 / 69, p=0.039)$.

Moreover, the incidence of RSA was higher in the 1970-2000 time period than in the 20002017 time period $(14 / 32$ vs. $14 / 78, p=0.005)$. But classification by age did not reveal any particular association. More importantly, the history of radiotherapy did not influence the lesion size, the rate of spontaneous splenic rupture or the development of benign splenic hemangioma $(p>0.05)$.

\section{The factors influencing the overall survival time (OS) of PSA}

Similar to angiosarcoma of other sites, the prognosis is poor for patients with PSA and survival time greater than 1 year is extremely rare [20]. Most patients do not survive the post-operative period or die within a few months after diagnosis. In the present study, we summarized the outcome of 94 patients with intact follow-up information. Kaplan-Meier and log-rank test methods were used to analyze potential significant prognostic factors including gender, age, splenic rupture and type of treatment.

From our analysis, we found that uncontrolled bleeding or metastases were common direct causes of death. Average survival time was approximately 8.1 months, with a range from 3 days to 60 months after definitive diagnosis. Overall, the 1-year OS rate was 19.1\% and was not associated with age or gender. Significant prognostic factors are shown in Fig. 1. There was no evidence of an improved outcome for PSA patients after 2000 when compared to those diagnosed before 2000. There was no evidence of an improved outcome for PSA patients after 2000 when compared to those diagnosed before 2000. Radiotherapy prior to the occurrence of splenic angiosarcoma did not affect OS significantly (median OS of 7.4 months in patients with radiotherapy history vs. 11.8 months in patients without, $p=0.4685$ ). PSA tumor size $>5 \mathrm{~cm}$ was a critical factor associated with adverse clinical outcome (median OS of 5.7 months vs. 9.0 months in patients with tumors $\leq 5 \mathrm{~cm}$ ). Corresponding 1-year survival rates were $7 \%$ in patients with tumors $>5 \mathrm{~cm}$ and $70 \%$ in patients with smaller tumors. From the survival analysis of 66 patients with information of pathological features, we found that the non-vasoformative architectural pattern was associated with inferior outcomes (median OS of 6 months for non-vasoformative vs. 9.47 months for vasoformative tumors, $p=0.5041$ ), though this did not achieve statistical significance. Similarly, a history of benign spleen hemangioma had no impact on clinical outcome.

In addition, splenic rupture prior to surgery was associated with a significantly shorter OS. The impact of spontaneous splenic rupture on PSA outcome is shown in Fig. 2. Patients 
Fig. 1. (A, B) Age and gender did not influence OS of primary splenic angiosarcoma. (C) Patients with primary splenic angiosarcoma did not show a longer survival after 2000s, when compared to those before 2000s. (D) History of radiotherapy did not influence the outcome of primary splenic angiosarcoma.

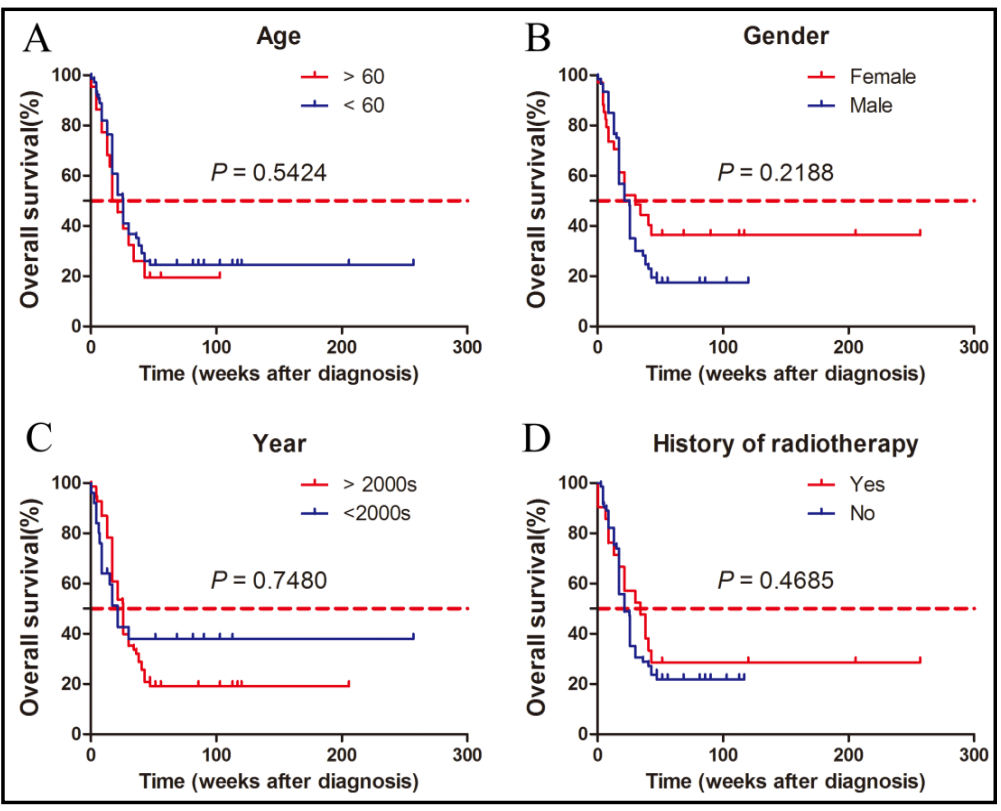

Fig. 2. Characters of tumor and treatment influence the prognosis of primary splenic angiosarcoma. (A, B) Tumor size $(>5 \mathrm{~cm})$ or metastatic lesion shortens the OS significantly in patients with primary splenic angiosarcoma. (C) Splenic rupture prior to surgery plays a negative role in OS of primary splenic angiosarcoma patients. (D) Adjuvant chemotherapy helps prolong the OS of primary splenic angiosarcoma significantly. (E, F) Histological type and history of benign spleen hemangioma did not impact the OS.
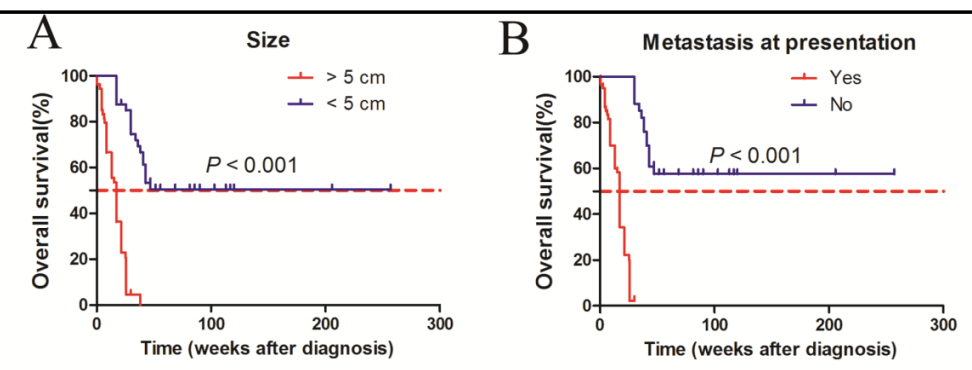

C

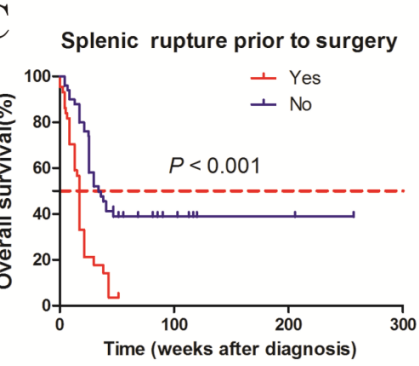

$\mathrm{D}$

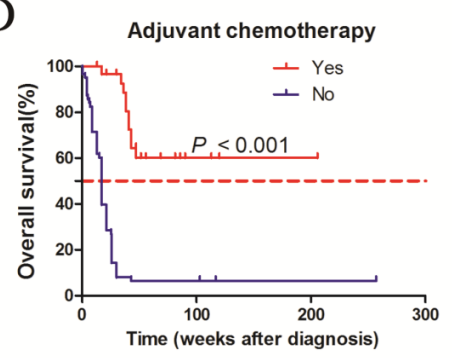

E

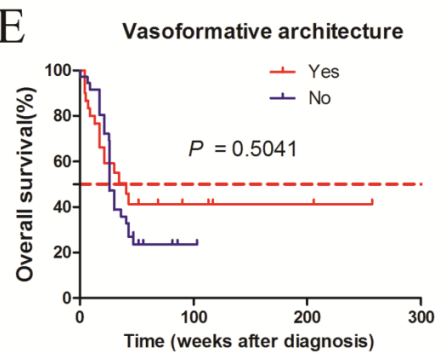

$\mathrm{F}$

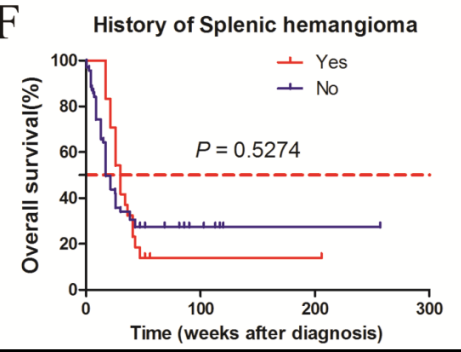




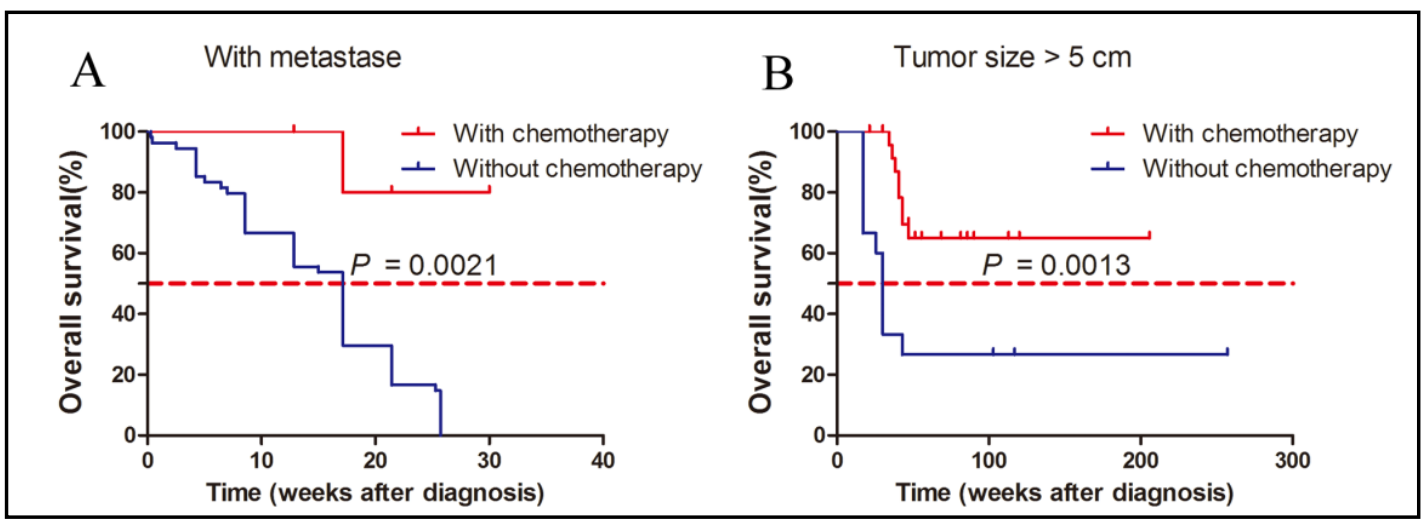

Fig. 3. Adjuvant chemotherapy helps improve outcome of primary splenic angiosarcoma significantly, even in the patients with a large mass $(>5 \mathrm{~cm})(\mathrm{A})$ or metastatic lesions (B).

who experienced splenic rupture had a median overall survival of 3.9 months vs. 7 months in those without $(p<0.001)$. Metastatic disease at first presentation was also associated with a shorter OS $(p<0.001)$. However, adjuvant chemotherapy was strongly associated with significantly improved PSA survival (median OS > 12 months in patients with adjuvant chemotherapy vs. 4 months in those without, $p<0.001$ ). Moreover, the association between adjuvant chemotherapy on OS was independent of the impact of spontaneous splenic rupture (median OS in patients with spontaneous splenic rupture: 10 months with chemotherapy vs. 3 months without chemotherapy, $p=0.0021$ ). Adjuvant chemotherapy was also associated with prolonged survival time in those patients with tumors larger than $5 \mathrm{~cm}(p=0.0013)$ (Fig. 3).

Univariate and multivariate analysis of factors which might indicate the prognosis of PSA

It was worthwhile to consider major determinants in the prognosis of PSA. Therefore, Cox proportional hazards regression models were introduced. As univariate analyses (Table 4) displayed that patients with tumors measuring $5 \mathrm{~cm}$ or less showed a significantly better prognosis than those with tumors larger than $5 \mathrm{~cm}(p=0.045)$. Patients with splenic rupture prior to surgery showed a significantly worse prognosis than those without $(p=0.035)$. But adjuvant chemotherapy did help improve the prognosis of PSA significantly. However, other clinical factors including gender, age, decade, history of benign splenic hemangioma, emergency surgery were not correlated to survival $(p>0.05)$. Subsequent multivariate analysis was performed on these three significant factors for survival. As Table 5 displayed that the occurrence of splenic rupture prior to surgery was an independent adverse predictor for outcome of PSA ( $p=0.009$ ), while the adjuvant therapy was a favorable one with a similar $\operatorname{HR}(p=0.014)$.
Table 4. Univariate cox analysis of survival in 94 patients with primary splenic angiosarcoma

\begin{tabular}{lc}
\hline Characteristics & HR(95\%CI) \\
\hline Year (after 2000/before 2000) & $0.861(0.291-2.550)$ \\
Gender (female/male) & $1.410(0.476-4.182)$ \\
Age (year) $(>60 / \leq 60)$ & $3.221(0.921-11.262)$ \\
Tumor size $(>5 \mathrm{~cm} / \leq 5 \mathrm{~cm})$ & $0.217(0.049-0.967)$ \\
Splenic rupture prior to surgery (no/yes) & $0.121(0.017-0.864)$ \\
History of benign spleen hemangioma (no/yes) & $4.919(0.634-38.179)$ \\
Emergency surgery (no/yes) & \\
Adjuvant chemotherapy (no/yes) & $0.914(0.179-4.673)$ \\
\hline
\end{tabular}

Table 5. Multivariate cox analysis of survival in 94 patients with primary splenic angiosarcoma

\begin{tabular}{lcc}
\hline Characteristics & HR(95\%CI) & p Value \\
\hline Tumor size $(>5 \mathrm{~cm} / \leq 5 \mathrm{~cm})$ & $0.242(0.049-1.207)$ & 0.084 \\
Splenic rupture prior to surgery (no/yes) & $0.083(0.013-0.542)$ & 0.009 \\
Adjuvant chemotherapy (no/yes) & $0.072(0.009-0.588)$ & 0.014 \\
\hline
\end{tabular}




\section{Cellular Physiology Cell Physiol Biochem 2018;49:1959-1969 \\ \begin{tabular}{ll|l} 
and Biochemistry & $\begin{array}{l}\text { DOI: 10.1159/000493656 } \\
\text { Published online: } 21 \text { September, } 2018\end{array}$ & $\begin{array}{l}\text { C } 2018 \text { The Author(s). Published by S. Karger AG, Basel } \\
\text { www.karger.com/cpb }\end{array}$ \\
\hline
\end{tabular}}

\section{Discussion}

PSA is a highly malignant vascular tumor, also known as a malignant vascular endothelial cell tumor, that rarely occurs in the spleen. Spleen angiosarcoma accounts for less than $1 \%$ of all types of sarcomas, and approximately $30 \%$ of these develop spontaneous splenic rupture [6].

The characteristics of the PSA patients in our cohort are generally consistent with angiosarcomas reported in other sites $[12,21]$. Although PSA occurs primarily in older patients, individuals of any age could be affected. In our study, PSA patients presented at widely varying ages, from 30 months to 76 years old. This disease shows a slight gender predilection for males, with an approximate male to female ratio of 1.7.

Clinical symptoms were non-specific and varied from asymptomatic diseases, found only on incidental investigations, to splenic rupture or lethal hemorrhage [15, 22, 23]. From the present study, a series of manifestations could be concluded as first presentations in PSA. Most patients presented with abdominal pain in our series, making it one of the most frequent first clinical presentations. Other common complaints included anorexia, fatigue and weight loss. Fever, as an associated finding, has also been described in nearly $12 \%$ of PSA patients.

As a result of extremely low incidence and non-specific symptoms, misdiagnosis was frequent during the first hospitalization. As displayed in Table 2, the diseases most often requiring differentiation from PSA included splenic metastatic malignancy, benign splenic hemangioma and malignant lymphoma. The distinctive manifestations of this tumor and difficult diagnosis combined with high mortality make early discovery very important. While a current lack of standardization remains, the diagnosis of PSA was made via surgery combined with pathologic investigation in all cases included in this study. Though not evaluated, imaging studies could prove useful for more definitive diagnosis and qualitative description [24]. In the present study, ultrasound, CT and MRI all provided supportive evidence of splenomegaly in most patients. Additionally, CT imaging was valuable for acute assessment of complications. Moreover, fine-needle aspiration cytology appeared advantageous in early diagnosis when there was a consideration of PSA without laparotomy $[25,26]$. Collectively, PSA should be considered in the differential diagnosis of patients with splenomegaly, especially when there is anemia of unknown etiology.

The pathogenesis of PSA is still unclear, though possible causative factors have been suggested $[16,27]$. The prevalence of sarcomas in the general population is very low, but it is relatively high among long-term survivors of primary tumors initially treated with irradiation. It has been reported that radiation-induced sarcomas constitute $18-30 \%$ of the postradiation malignancies [28]. The frequency of radiation-associated splenic angiosarcoma in our cohort was approximately $25 \%$, which was consistent with other publications $[29,30]$. All cases received radiotherapy to control their primary malignancies. With an increasing number of patients who are cured of their primary malignancies, especially after application of radiotherapy in gynecological system tumors [31,32]_ENREF_7, a rise in the prevalence of radiation-associated sarcomas was to be expected as a serious, often lethal, complication. The median duration between radiotherapy and occurrence of post-radiation angiosarcoma in our series was 9.5 years. Additionally, we found that there was a predilection for females and a decreased incidence after 2000 in the post-radiation-associated splenic angiosarcoma. Radiotherapy did not influence the onset age, tumor size, or rate of spontaneous splenic hemorrhage. Notably, the shortest interval between radiotherapy and occurrence of postradiation angiosarcoma was 4 years after initial radiation treatment for prostate cancer, highlighting the necessity for clinical vigilance even during early radiation therapy followup. In the present study, we aimed to explore the factors impacting PSA outcomes.

Compared to sporadic angiosarcomas, radiation-associated splenic angiosarcoma patients did experience different survival outcomes. Limited by our retrospective cohort design, we were only able to collect intact descriptions of histological appearance from 66 patients. Consistent with the current consensus statement from the American Joint 
Committee on Cancer and College of American Pathologists [33], the grading of angiosarcoma did not correlate with prognosis according to our analysis. As suggested by Mark et al., well-differentiated tumors can behave aggressively [34]. However, Naka et al. found that mitotic count was an independent factor for worse prognosis in a multivariate analysis of 55 angiosarcoma cases [35]. Deyrup et al. found that epithelioid morphology and necrosis were associated with poorer prognosis in a series of sporadic cutaneous angiosarcomas [36]. Thus, there is still debate regarding the role of histological grading in PSA prognosis. Of note, our experience was limited by small numbers. Further analysis is needed to settle this dispute.

Large tumor size $(>5 \mathrm{~cm})$ and the presence of metastatic disease at diagnosis were shown to negatively influence the prognosis of PSA. Lesion size appears to be an important prognostic factor in many studies. Mark et al. have reported a 5-year survival rate of $13 \%$ for those with tumors larger than $5 \mathrm{~cm}$ compared with $32 \%$ for those with smaller lesions [34]. The reported rates of metastases in PSA were 69-100\% [6, 7, 12]. Secondary malignant tumors can occur mainly by hematogenous spread or direct invasion. The most common site involved is the liver, followed by the lung, bone, lymph nodes and ovaries [37, 38]. In the present study, most patients had metastases, in spite of the fact that the primary lesion has been removed, that led to their deterioration. While angiosarcoma is known to be a highly metastatic disease, it has also been speculated that surgical intervention might increase the risk of distant metastases.

Apart from the extremely malignant character, rupture of splenic angiosarcoma contributes to poor prognosis, with an immediate risk of death from hemorrhagic shock and disseminated intravascular coagulopathy. The rupture of the splenic tumor also facilitates peritoneal dissemination and hematogenous spread. Though there is currently no consensus regarding the treatment of PSA, splenectomy is regarded as the preferred treatment for spleen angiosarcoma, as it has improved outcomes even in patients with aggressively disseminated metastases, especially when it is performed before splenic rupture. Montemayor et al. found that that splenectomy prolonged survival from 4.4 months to 14.4 months [37]. All patients had a splenectomy in the present study, and we found that surgery before rupture was associated with a much longer overall survival time. Moreover, multivariate Cox analysis indicated that a lack of intervention before rupture of splenic angiosarcoma exacerbated poor outcomes and was an independent predictor of unfavorable prognosis.

Concurrent chemotherapy was a promising choice for improved outcomes, and it was advantageous both in the entire series and in the subgroup of patients who presented with metastatic lesions. However, currently, there are still no specific chemotherapeutic regimens for treating splenic angiosarcoma. Most treatment programs were designed empirically, owing to the lack of evidence from large-scale studies. Administration of IL-2 was not significantly associated with survival [35]. Recently, the therapeutic efficacy of autologous peripheral blood stem cell transplantation, based on chemotherapy, has been reported [39]. However, its value still needs further investigation.

\section{Conclusion}

In conclusion, our study provides the first overview of demographics, tumor characteristics and treatment outcomes of a large series of Chinese PSA patients. Our data indicate that radiation-associated PSA is a distinct type of PSA but shares a similar outcome. Large tumor size $(>5 \mathrm{~cm}$ ) or metastatic diseases will worse PSA outcome. Adjuvant chemotherapy is beneficial, even in patients with metastatic disease. Splenic rupture has been demonstrated to be an independent indicator of adverse outcomes; early diagnosis and surgical resection prior to rupture are independent indicators for improved prognosis. Collectively, we anticipate that these observations will provide a warning for clinicians. We strongly suggest that PSA patients will benefit from early diagnosis, intervention prior to 


\section{Cellular Physiology Cell Physiol Biochem 2018;49:1959-1969

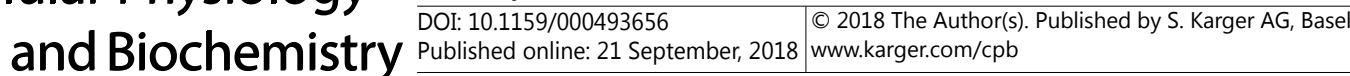 \\ Li et al.:Clinical Characteristics and Prognostic Factors of Primary Splenic Angiosarcoma}

splenic rupture, and multi-disciplinary management by teams with broad expertise in the pathologic examination and systemic management of this rare malignancy.

\section{Acknowledgements}

This work was supported by grants from the National Natural Scientific Foundation of China (No. 81570509), the New Xiangya Talent Project of the Third xiangya hosipital of Central South University (No. 20150310) and Changsha Science and Technology Project (No. kq1701091).

\section{Disclosure Statement}

No conflict of interests exists.

\section{References}

1 Coindre JM, Terrier P, Guillou L, Le Doussal V, Collin F, Ranchere D, Sastre X, Vilain MO, Bonichon F, N'Guyen Bui B: Predictive value of grade for metastasis development in the main histologic types of adult soft tissue sarcomas: a study of 1240 patients from the French Federation of Cancer Centers Sarcoma Group. Cancer 2001;91:1914-1926.

2 Liu Q, Ouyang R, Chen P, Zhou R: A case report of retiform hemangioendothelioma as pleural nodules with literature review. Diagn Pathol 2015;10:194.

3 Tang K, Shang QL, Zhou QC, Zhou JW, She XL, Zhang M: Primary cardiac angiosarcoma with spontaneous ruptures of the right atrium and right coronary artery. Echocardiography 2013;30:E156-160.

-4 Li R, Ouyang ZY, Xiao JB, He J, Zhou YW, Zhang GY, Li Q Gu H, Leng AM, Liu T: Clinical Characteristics and Prognostic Factors of Small Intestine Angiosarcoma: a Retrospective Clinical Analysis of 66 Cases. Cell Physiol Biochem 2017;44:817-827.

5 Takato H, Iwamoto H, Ikezu M, Kato N, Ikarashi T, Kaneko H: Splenic hemangiosarcoma with sinus endothelial differentiation. Acta Pathol Jpn 1993;43:702-708.

6 Falk S, Krishnan J, Meis JM: Primary angiosarcoma of the spleen. A clinicopathologic study of 40 cases. Am J Surg Pathol 1993;17:959-970.

7 Neuhauser TS, Derringer GA, Thompson LD, Fanburg-Smith JC, Miettinen M, Saaristo A, Abbondanzo SL: Splenic angiosarcoma: a clinicopathologic and immunophenotypic study of 28 cases. Mod Pathol 2000;13:978-987.

8 He P, Yan XD, Wang JR, Guo RC, Zhang HB: Splenic littoral cell hemangioendothelioma: report of a case with hepatic metastases and review of the literature. J Clin Ultrasound 2014;42:308-312.

-9 Kamocki Z, Steward A, Zareba KP, Kuklinski A, Kedra B: Primary splenic angiosarcoma - the same diagnosis yielding two different clinical pictures. Case report. Contemp Oncol (Pozn) 2013;17:218-221.

$>10$ Hsu JT, Chen HM, Lin CY, Yeh CN, Hwang TL, Jan YY, Chen MF: Primary angiosarcoma of the spleen. J Surg Oncol 2005;92:312-316.

-11 den Hoed ID, Granzen B, Granzen B, Aronson DC, Pauwels P, de Kraker J, van Heurn LW: Metastasized angiosarcoma of the spleen in a 2-year-old girl. Pediatr Hematol Oncol 2005;22:387-390.

12 Naka N, Ohsawa M, Tomita Y, Kanno H, Uchida A, Aozasa K: Angiosarcoma in Japan. A review of 99 cases. Cancer 1995;75:989-996.

13 Aqil B, Green LK, Lai S: Primary splenic angiosarcoma associated with anemia, leukocytosis and thrombocytopenia. Ann Clin Lab Sci 2014;44:217-221.

14 Rosenblatt P, Koka R, Chen Q Papadimitriou JC, Sausville EA, Emadi A: Schistocytes, echinocytes, iron deficiency anemia, and thrombocytopenia - hematologic manifestations of splenic angiosarcoma. Arch Iran Med 2013;16:602-605.

15 Badiani R, Schaller G, Jain K, Swamy R, Gupta S: Angiosarcoma of the spleen presenting as spontaneous splenic rupture: A rare case report and review of the literature. Int J Surg Case Rep 2013;4:765-767. 


\section{Cellular Physiology Cell Physiol Biochem 2018;49:1959-1969

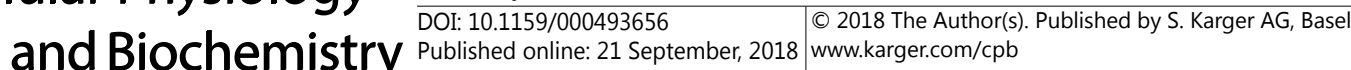 \\ Li et al.:Clinical Characteristics and Prognostic Factors of Primary Splenic Angiosarcoma}

-16 Young RJ, Brown NJ, Reed MW, Hughes D, Woll PJ: Angiosarcoma. Lancet Oncol 2010;11:983-991.

17 Koplin SA, Twohig MH, Lund DP, Hafez GR: Omental lipoblastoma. Pathol Res Pract 2008;204:277-281.

18 Nanus DM, Kelsen D, Clark DG: Radiation-induced angiosarcoma. Cancer 1987;60:777-779.

19 Westenberg AH, Wiggers T, Henzen-Logmans SC, Verweij J, Meerwaldt JA, van Geel AN: Post-irradiation angiosarcoma of the greater omentum. Eur J Surg Oncol 1989;15:175-178.

20 Chami TN, Ratner LE, Henneberry J, Smith DP, Hill G, Katz PO: Angiosarcoma of the small intestine: a case report and literature review. Am J Gastroenterol 1994;89:797-800.

-21 Abraham JA, Hornicek FJ, Kaufman AM, Harmon DC, Springfield DS, Raskin KA, Mankin HJ, Kirsch DG, Rosenberg AE, Nielsen GP, Desphpande V, Suit HD, DeLaney TF, Yoon SS: Treatment and outcome of 82 patients with angiosarcoma. Ann Surg Oncol 2007;14:1953-1967.

-22 Duan YF, Jiang Y, Wu CX, Zhu F: Spontaneous rupture of primary splenic angiosarcoma: a case report and literature review. World J Surg Oncol 2013;11:53.

-23 Yoshida K, Endo T, Kamata K, Aisawa H, Konuma Y, Ogasawara H, Yoshihara A, Kusumi T, Fukuda S: [A case of angiosarcoma of the spleen with intraperitoneal bleeding]. Nihon Shokakibyo Gakkai Zasshi 2014;111:549-556.

24 Qiu LL, Yu RS, Chen Y, Zhang Q: Sarcomas of abdominal organs: computed tomography and magnetic resonance imaging findings. Semin Ultrasound CT MR 2011;32:405-421.

25 Grapsa D, Sakellariou S, Politi E: Fine-needle aspiration cytology of primary renal angiosarcoma with histopathologic and immunocytochemical correlation: a case report. Diagn Cytopathol 2014;42:872-876.

26 Delacruz V, Jorda M, Gomez-Fernandez C, Benedetto P, Ganjei P: Fine-needle aspiration diagnosis of angiosarcoma of the spleen: a case report and review of the literature. Arch Pathol Lab Med 2005;129:1054-1056.

27 Sordillo EM, Sordillo PP, Hajdu SI: Splenic angiosarcoma. Am J Surg Pathol 1995;19:119-120.

-28 Hansen SH, Holck S, Flyger H, Tange UB: Radiation-associated angiosarcoma of the small bowel. A case of multiploidy and a fulminant clinical course. Case report. APMIS 1996;104:891-894.

-29 Buehler D, Rice SR, Moody JS, Rush P, Hafez GR, Attia S, Longley BJ, Kozak KR: Angiosarcoma outcomes and prognostic factors: a 25-year single institution experience. Am J Clin Oncol 2014;37:473-479.

30 Lahat G, Dhuka AR, Hallevi H, Xiao L, Zou C, Smith KD, Phung TL, Pollock RE, Benjamin R, Hunt KK, Lazar AJ, Lev D: Angiosarcoma: clinical and molecular insights. Ann Surg 2010;251:1098-1106.

31 Garg G, Massad LS, Pourabolghasem S, Zhou G, Powell MA, Thaker PH, Hagemann AR, WilkinsonRyan I, Mutch DG: Intestinal perforation in gynecologic oncology: do all patients benefit from surgical management? Gynecol Oncol 2013;129:538-543.

32 Kim SI, Lim MC, Lee JS, Kim YJ, Seo SS, Kang S, Yoo CW, Nam BH, Kim JY, Chung SH, Park SY: Comparison of Lower Extremity Edema in Locally Advanced Cervical Cancer: Pretreatment Laparoscopic Surgical Staging with Tailored Radiotherapy Versus Primary Radiotherapy. Ann Surg Oncol 2016;23:203-210.

33 Rubin BP, Cooper K, Fletcher CD, Folpe AL, Gannon FH, Hunt JL, Lazar AJ, Montag AG, Peabody TD, Pollock RE, Reith JD, Qualman SJ, Rosenberg AE, Weiss SW, Krausz T, Members of the Cancer Committee CoAP: Protocol for the examination of specimens from patients with tumors of soft tissue. Arch Pathol Lab Med 2010;134:e31-39.

34 Mark RJ, Poen JC, Tran LM, Fu YS, Juillard GF: Angiosarcoma. A report of 67 patients and a review of the literature. Cancer 1996;77:2400-2406.

-35 Naka N, Ohsawa M, Tomita Y, Kanno H, Uchida A, Myoui A, Aozasa K: Prognostic factors in angiosarcoma: a multivariate analysis of 55 cases. J Surg Oncol 1996;61:170-176.

-36 Deyrup AT, McKenney JK, Tighiouart M, Folpe AL, Weiss SW: Sporadic cutaneous angiosarcomas: a proposal for risk stratification based on 69 cases. Am J Surg Pathol 2008;32:72-77.

37 Montemayor P, Caggiano V: Primary hemangiosarcoma of the spleen associated with leukocytosis and abnormal spleen scan. Int Surg 1980;65:369-373.

-38 Valbuena JR, Levenback C, Mansfield P, Liu J: Angiosarcoma of the spleen clinically presenting as metastatic ovarian cancer. A case report and review of the literature. Ann Diagn Pathol 2005;9:289-292.

-39 Hara T, Tsurumi H, Kasahara S, Ogawa K, Takada J, Imai K, Takai K, Kitagawa J, Kiyama S, Imai N, Oyama M, Takami T, Moriwaki H: Long-term survival of a patient with splenic angiosarcoma after resection, high-dose chemotherapy, and autologous peripheral blood stem cell transplantation. Intern Med 2010;49:2253-2257. 